\title{
The skill of recognizing musical structures
}

\author{
A. LYNNE BEAL \\ University of Waterloo, Waterloo, Ontario, Canada
}

\begin{abstract}
In three experiments, musicians and nonmusicians were compared in their ability to discriminate musical chords. Pairs of chords sharing all notes in common or having different notes were played in succession. Some pairs of chords differed in timbre independent of their musical structures because they were played on different instruments. Musicians outperformed nonmusicians only in recognizing the same chord played on different instruments. Both groups could discriminate between instrument timbres, although musicians did slightly better than nonmusicians. In contrast, with chord structures not conforming to the rules of tonal harmony, musicians and nonmusicians performed equally poorly in recognizing identical chords played on different instruments. Signal detection analysis showed that musicians and nonmusicians set similar criteria for these judgments. Musicians' superiority reflects greater sensitivity to familiar diatonic chords. These results are taken as evidence that musicians develop perceptual and cognitive skills specific to the lawful musical structures encountered in their culture's music. Nonmusicians who lack this knowledge based their judgments on the acoustical properties of the chords.
\end{abstract}

The perceptual and cognitive abilities that skilled individuals develop have been studied in chess (Charness, 1976; Chase \& Simon, 1973a, 1973b; deGroot, 1966; Frey \& Adesman, 1976); in bridge (Charness, 1979); in basketball (Allard, Graham, \& Paarsalu, 1980); in volleyball (Allard \& Starkes, 1980); and in reading circuit diagrams (Egan \& Schwartz, 1979). In each case, skilled individuals outperform their unskilled counterparts. They develop strategies for processing information specific to configurations which reflect the rules of their fields.

Studies of musical sight reading and auditory perception of melodies have shown that musicians develop special perceptual and cognitive skills for playing and listening to music. Musicians perceive musical structures which are unnoticed by nonmusicians. Good sight readers play fluently because they perceive familiar structures in musical scores, but poor sight readers play note by note (Sloboda, 1976a, 1976b, 1977; Wolf, 1976). Before starting to play, good sight readers analyze the tempo, key, and melodic structure of the passage, condensing the score into familiar patterns (Sloboda, 1977, 1978). Because atonal music lacks familiar patterns, it is more difficult to sight read; thus, good sight readers play it as poorly as poor sight readers do (Wolf, 1976).

All listeners use melodic context in some way to help them remember a specific pitch in a melody (see e.g.,

This paper is based on a doctoral thesis submitted to the University of Waterloo. A version of the paper was presented at the 41 st meeting of the Canadian Psychological Association, June, 1980. I am indebted to F. Allard and G. E. Mackinnon for their assistance and support in all phases of this research. I am grateful to C. D. Creelman for insightful comments on an earlier draft of the manuscript. Requests for reprints may be addressed to A. L. Beal, The Board of Education for the City of Toronto, Student Services, 155 College Street, Toronto, Ontario, Canada M5T 1 P6.
Deutsch, 1978; Deutsch \& Roll, 1974; Dewar, Cuddy, \& Mewhort, 1977; Olson \& Hanson, 1977). However, musicians and nonmusicians use the contextual cues of tonal intervals and melodic contour differently.

Nonmusicians use melodic contour, the pattern of increasing and decreasing frequencies, but do not use interval size when processing pitch (Dowling, 1978; Pick, 1979). Nonmusicians use the tonic scale on which the melody is based as concrete frequency anchors for subsequent tones (Krumhansl \& Shepard, 1979). Nonmusicians use melodic context to remember single tones (Dewar et al., 1977), but not to identify intervals (Cuddy, Cohen, \& Dewar, 1978). Even their ability to recognize pitch height depends largely on melodic contour typical of familiar Western music (Pick, 1979) and is decreased when pitch changes occur within identical melodic contours (Dowling, 1978; Dowling \& Fujitani, 1971).

In contrast, musicians use both types of contextual information in judging pitch (Dowling, 1978; Pick, 1979) as they organize pitch around the tonal structure of a context scale (Krumhansl \& Shepard, 1979). Musicians can determine the tonality or the diatonic scale associated with short melodies (Cohen, 1978; Cuddy, Cohen, \& Miller, 1979), and chords (Bharucha \& Krumhansl, 1983; Krumhansl, Bharucha, \& Castellano, 1982). They recognize equivalence of tones from different octaves and are sensitive to the musical goodness of intervals. They benefit from extra melodic context in remembering single tones (Dewar et al., 1977), intervals (Cuddy et al., 1978), and transposed short melodies (Cuddy \& Cohen, 1976).

The present research investigates the perceptual and cognitive skills that may serve musicians to yield superior performance in processing musical stimuli. Posner's (1969; Posner \& Warren, 1972) model of information processing and experimental paradigm will be used here to conceptualize the nature of musicians' skills. 
Posner's model explains how skilled individuals encode abstract visual information. He suggests that a stimulus first is captured intact as a physical code. Identification follows by processing the encoded stimulus to a representational code, or name code for letters. Name referents, built up through previous association and organized into long-term memory structures, are used in the identification process.

Posner's paradigm was adapted for studies on the encoding processes used in auditory identification of linguistic information by skilled language users. Listeners decided whether two speech stimuli presented sequentially had the same or different linguistic identities. Physical ambiguity was introduced by using a male and a female speaker. Whether judging phonemes (Cole, Coltheart, \& Allard, 1974) or words (Allard \& Henderson, 1976), listeners made "same"' decisions fastest when the two stim. uli were acoustically identical (said in the same voice). These data support physical and abstract coding in auditory information processing.

In the following three experiments, Posner's experimental paradigm is adapted to musical chords played on different instruments. Data from musicians and nonmusicians will be compared.

Posner's distinction between physical and abstract coding of stimuli by skilled individuals provides a framework for conceptualizing the nature of musicians' skills. Musicians may develop a conceptual understanding of diatonic chords which enables them to encode musical structures in abstract form. Thus, identical chords would be recognizable when played in different timbres. Nondiatonic chords lacking familiar musical structure would not be as easy to encode abstractly. Musicians may judge nondiatonic chords played in different timbres to be different, just as nonmusicians may depend more heavily on acoustic information when judging chords. They may not recognize the structural similarity in diatonic or nondiatonic chords played on different instruments.

\section{EXPERIMENT 1}

The first experiment compared musicians' and nonmusicians' judgments of similarity in chords. The task was for subjects to decide whether two chords played sequentially contained the same notes. On some trials the chords were played on different instruments, introducing irrelevant acoustic variation into the task. Instruments differ acoustically in timbre, the simultaneous presence or fusion of the fundamental with its overtones characteristic of an instrument at a given moment (Benade, 1976).

Musicians are expected to outperform nonmusicians in this task because they can detect musical similarity in spite of variations in timbre. Signal detection analysis (Kaplan, Macmillan, \& Creelman, 1978; Macmillan, Kaplan, \& Creelman, 1977) will be used to show that musicians' greater sensitivity is due to their specific knowledge about chord structures.

\section{Method}

Subjects. Twenty-four University of Waterloo undergraduate and graduate students, having no hearing impairments, participated as listeners. Twelve listeners, "musicians," had passed at least eight grades of practical music and two grades of music theory (Royal Conservatory of Music of Toronto or equivalent). Twelve "nonmusicians" had less than four years of musical training.

Materials. The stimuli were chords played on an Epiphone sixstring acoustic guitar, a Baldwin piano, and a Zuckerman Flemish harpsichord. The instruments were tuned to the piano $(A=440 \mathrm{~Hz})$.

Two sets of four-note chords shown in Figure 1 were used as stimuli. The chords in Set 1 were $\mathrm{E}$ major, A major, C minor, the diminished seventh of $\mathrm{E}$ minor, and the dominant seventh of $G$ major. Set 2 comprised identical chord structures, transposed a few notes: $G$ major, $E$ major, A minor, the diminished seventh of $\mathrm{F}$ minor and the dominant seventh of $\mathrm{C}$ major. One version of each chord was chosen which kept all its notes in the frequency range from $D(146.83 \mathrm{~Hz})$ to $\mathrm{G}(392 \mathrm{~Hz})$. For the triad chords the bottom note was repeated one octave higher to make a fourth note (i.e., E major was made of $E, G \#, B, E$ ).

All chords were played on each instrument, recorded, and then digitized through a 12-bit A/D converter connected to a PDP 11/40 computer. The chords were equated in duration by using the first $500 \mathrm{msec}$ of each. The onset amplitude envelope was unmodified in the first $350 \mathrm{msec}$, but was decreased linearly to zero over the remaining $150 \mathrm{msec}$. Loudness was equated by adjusting overall amplitude for equal deflection on a VU meter. Each resulting chord was stored in a digital sound library for recording on audio tape.

Design. Experimental tapes were made under the control of a program which selected chords and controlled the sequence and timing of presentations. Each trial consisted of two chords, separated by $1 \mathrm{sec}$. A pause of $5 \mathrm{sec}$ separated the trials. Two tapes were made using Chord Set 1, one played on harpsichord and guitar (HG) and one played on piano and guitar (PG). Two tapes were made using Chord Set 2 with the same pairs of instruments.

Each tape contained 120 trials. For 60 trials the same chord was presented twice, and for 60 trials different chords were played. Of the 60 same-chord pairs, 30 were played on the same instrument (e.g., both on piano or both on guitar), and 30 were played on different instruments (e.g., one on piano and one on guitar). The same counterbalancing was used for the 60 pairs with different chords. Within these constraints, stimuli were ordered randomly.

Presentation of pairs of musical instrument and chord sets was counterbalanced across both musicians and nonmusicians. Half of each group of listeners heard chords played on harpsichord and guitar, and half heard the piano and guitar chords. These groups were further divided so that half heard Set 1 and half heard Set 2 .

Procedure. Each listener was tested individually in one session lasting about $90 \mathrm{~min}$. The task was explained, and five practice trials were played; then there was a discussion period for questions raised by the listener. Each listener completed three blocks of 120 trials, separated by 5 -min rest intervals. The chords were presented binaurally over headphones at a comfortable listening level.
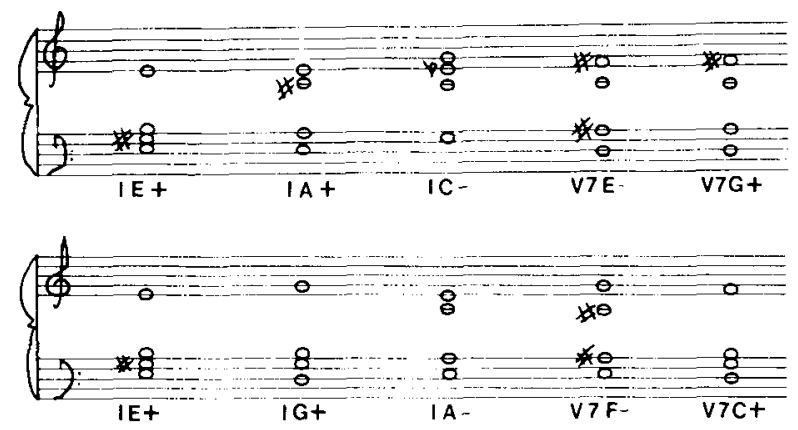

Figure 1. Diatonic Chord Sets 1 and 2 used in Experiment 1. 
Listeners indicated for each trial whether the two chords were the same, sharing all four notes or frequencies in common, or different, containing different notes. Listeners were instructed to ignore the sound of the instruments playing the chords (timbre) as it was irrelevant to the task. Listeners were told to respond as quickly as they could without making errors. Responses were made by pressing buttons marked "same" and "different." Half of the listeners responded "same" with the right forefinger and "different" with the left forefinger, and the buttons were reversed for the remaining listeners. Each response was scored as correct or incorrect, and the response time, from the onset of the second chord until the response, was recorded manually from a digital timer.

\section{Results}

Reaction time. The median reaction time (RT) for correct responses in each experimental condition was computed for each listener. As some nonmusicians had no correct responses for pairs containing the same chord played on different instruments, no valid estimate of a latency for correct judgments in this experimental condition could be made. Thus, RT analyses were computed only for musicians' data.

Figure 2 shows the mean RTs in each experimental condition. The only significant result was that musicians' RTs were longer for chord pairs played on different instruments than on the same instrument $[\mathrm{F}(1,11)=12.85$, $\mathrm{p}<.005]$. In the analysis of variance, chord pairs (same or different), instruments (same or different), and trial blocks $(1,2$ or 3$)$ were within-subject variables.

Discrimination. Discrimination data were based on error scores. Figure 3 presents mean percentage of errors for each group of listeners judging the four types of chord pairs, averaged over the three blocks of trials.

Practice improved the performance of both musicians and nonmusicians $[\mathrm{F}(2,40)=8.2, \mathrm{p}<.005]$. As this effect was not significantly different across experimental conditions and no significant interaction involved this variable, the data were collapsed for graphic presentation.

Musicians outperformed nonmusicians mainly when the same chord was played on different instruments [interaction $F(1,20)=9.24, p<.01]$, although both groups made more errors with such stimuli [interaction $\mathrm{F}(1,20)$



Figure 2. Median reaction time for correct responses by musicians in Experiment 1.

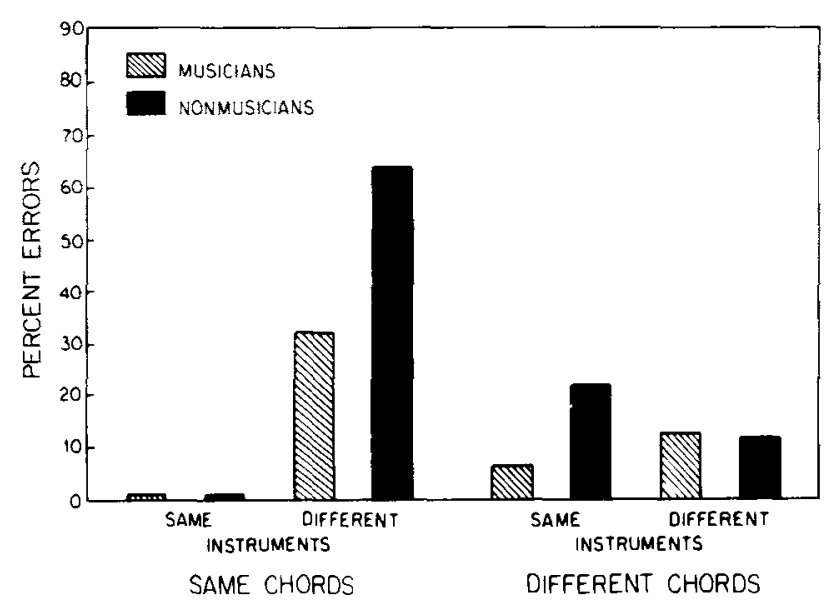

Figure 3. Mean error percentages for chord discriminations by musicians and nonmusicians in Experiment 1.

$=34.44, \mathrm{p}<.001]$. Nonmusicians' average error rate for these judgments was $64 \%$, considerably higher than their average error rate of $22 \%$ when judging different chords played on the same instrument $[t(11)=4.61$, $\mathrm{p}<.001]$. The analysis of variance had instrument pairs (PG or HG) and training (musicians or nonmusicians) as between-subject variables. Chord pairs (same or different), instruments (same or different), and trial blocks (1, 2 or 3 ) were within-subject variables.

On average, both groups made more errors when chords were the same $(24 \%)$ than when they were different $(14 \%)$ $[\mathrm{F}(1,20)=6.84, \mathrm{p}<.025]$. Musicians outperformed nonmusicians when the same chord was repeated on different instruments [interaction $F(1,22)=44.87, p<$ $.001]$; the two groups performed equally well when the same chord was repeated on the same instrument. In contrast, musicians outperformed nonmusicians in discriminating different chords only when chords were played on the same instrument [interaction $F(1,22)=6.32$, $\mathrm{p}<.025]$. The groups were equally accurate in determining that different chords had been played on different instruments.

Macmillan, Kaplan, and Creelman (1977) developed an analysis of same-different data on the basis of extensions of Signal Detection Theory. This analysis, although based on the familiar $2 \times 2$ matrix, is complicated because judgment is based on the difference between two observations on each trial. Kaplan, Macmillan, and Creelman (1978) published tables for analysis of these data. On this basis, we find $\mathrm{d}^{\prime}=2.93$ for musicians on trials with different instruments, while nonmusicians gave a lower $\mathrm{d}$ ' $=2.09$. This difference arises entirely from the "hit rate," the likelihood of calling an identical chord played on different instruments the same, with $68 \%$ hits for musicians and $36 \%$ for nonmusicians. The proportion of "false alarms," calling different chords played on the same instrument the same, was almost identical, at $13 \%$ and $14 \%$ for the two groups. So nonmusicians were less able to identify identical chords as the same when they 
were played on different instruments. Looked at another way, nonmusicians almost always heard two chords played on different instruments as different, whether or not they were musically the same.

On trials with identical instruments, discriminability could not be evaluated, since both groups of listeners had hit rate proportions over $99 \%$, providing unstable estimates. Even here, however, the false-alarm rates perhaps can be instructive. Musicians had fewer false alarms, $7 \%$, compared to nonmusicians' $22 \%$. On these trials, nonmusicians seemed more willing to call two chords the same when the two stimuli were identical in the instrument used but not in musical structure. Considering these two sets of data together, and remembering that trials with identical and different instruments were unpredictably intermixed, we can infer that the nonmusicians listened differently, paying more attention to timbre and less attention to musical structure.

\section{Discussion}

Musicians recognized the same chord in different timbres because they could encode the musical relations among the component notes of the chords. Musicians reported using such strategies as identifying chords by type (major, minor, dominant, or diminished) and by component intervals. Some claimed to listen for the progression made by a pair of chords, and to judge lack of progression or change or transposition to indicate a repetition of the same chord. Some compared the tonics of the chords, a strategy reported by Bharucha and Krumhansl (1983) and Krumhansl et al. (1982).

The usable reaction time data support this analysis. Musicians took more time to determine musical similarity in chords which had different timbres, because their decisions required musical coding. Their performance parallels the performance of skilled language users who took longer to recognize similar speech sounds in different voices (e.g., Cole et al., 1974).

Nonmusicians' difficulty parallels that of Howell and Darwin's (1977) listeners who discriminated poorly between phonemes having ambiguous identities. In both cases, the listeners lack a name or representational code which could map onto both stimuli despite their acoustic differences. Without a suitable coding system, listeners processed the stimuli acoustically, not recognizing conceptual invariance.

Musicians are not simply better listeners than nonmusicians. Their competence in recognizing identical chords played in different timbres seems to reflect specific knowledge about chords. Their competence also may involve greater skill in auditory analysis. Musicians should outperform nonmusicians in nonmusical discrimination if this is the case. This possibility is tested in the next experiment.

\section{EXPERIMENT 2}

In Experiment 2, we examine how well musicians and nonmusicians can make auditory discriminations which are not related to the rules of music. Discrimination of instrument timbre was chosen as the task, using the stimuli from Experiment 1. There is some evidence that timbre discrimination, as measured by the Seashore Measures of Musical Talent (Seashore, 1919), is a poor predictor of musical talent. Despite the underlying assumption that performance on sensory tasks can predict musical talent, scores on the timbre subtest have low (.50) concurrent validity (Buros, 1965). Thus we might expect nonmusicians to discriminate timbre as accurately as musicians.

An important comparison is of nonmusicians in Experiment 1 who judged the chords and nonmusicians in Experiment 2 who judged instruments. Nonmusicians are expected to make timbre discriminations more accurately than chord discriminations. This result would provide evidence that nonmusicians possess adequate auditory sensitivity.

\section{Method}

Subjects. Twenty-four University of Waterloo students volunteered as listeners; 12 were musicians and 12 were nonmusicians. None had participated in Experiment 1.

Materials. The stimulus materials were the four audio tapes used in Experiment 1. Half of each group of listeners heard Chord Set 1 while the remaining listeners heard Set 2 . Each listener completed two blocks of 120 trials, one block played on PG and one on HG. Half of the listeners heard the PG block first, and half of them heard the HG block first.

Procedure. The procedure was the same as in Experiment 1, except that the listeners' task was to decide whether the two chords in each trial were played on the same instrument (e.g., both on piano) or on two different instruments (e.g., one on piano and one on guitar). The notes and musical structures of the chords were to be ignored. Listeners recorded on prepared answer sheets " $S$ " to indicate the same instrument and " $D$ " for different instruments.

\section{Results}

The mean percentage of errors for each type of stimulus pair is shown in Figure 4. Notice the tiny error rates (all less than 15\%) in contrast to Experiment 1 (up to $64 \%)$.

Only in judging the same instrument playing different chords did musicians outperform nonmusicians [inter-

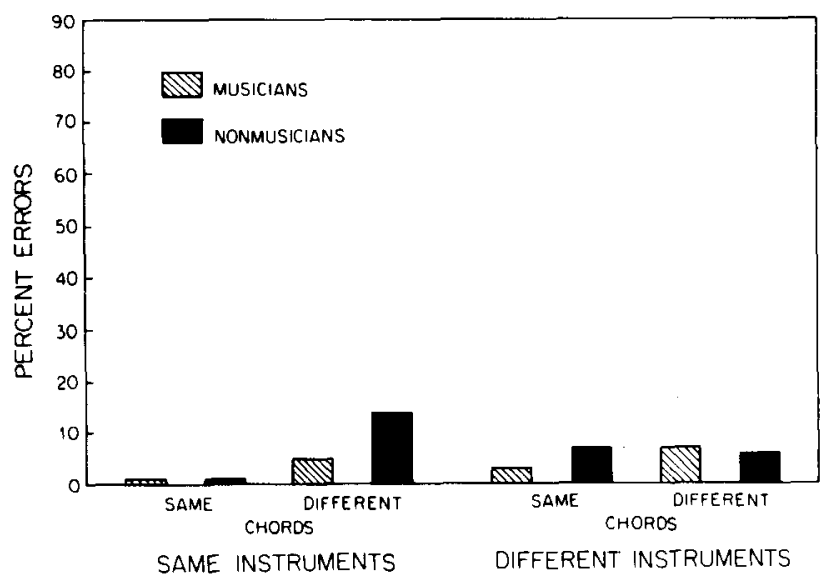

Figure 4. Mean error percentages for instrument discriminations by musicians and nonmusicians in Experiment 2. 
action $\mathrm{F}(1,18)=4.75, \mathrm{p}<.01]$. Musicians' $95 \%$ hit rate for judging the same instrument playing different chords was significantly higher than nonmusicians' $86 \%$ hit rate. False alarms for different instruments playing the same chord were equally low, $7 \%$ for musicians and $6 \%$ for nonmusicians. Musicians' sensitivity $\left(\mathrm{d}^{\prime}=4.86\right)$ was greater than nonmusicians' $\left(d^{\prime}=4.29\right)$.

Meaningful $\mathrm{d}^{\prime}$ values could not be computed for pairs with the same instrument and same chord, where hit rates were $99 \%$ for both groups. Low false alarm rates, $3 \%$ for musicians and $7 \%$ for nonmusicians judging pairs with with different instruments and different chords indicate that musicians and nonmusicians used similar criteria for judging similarity of instrument timbres.

Nonmusicians made many fewer errors recognizing identical instruments in Experiment 2 than identical chords in Experiment 1 for stimuli that were different in the irrelevant dimension (e.g., same instrument playing different chords in Experiment 2) [t(20) $=12.13, \mathrm{p}<.001]$. Nonmusicians judged acoustically identical stimuli (same chord played on the same instrument) with similar accuracy, whether asked to judge chords or instruments $[\mathrm{t}(20)=.08, \mathrm{p}>.05]$.

\section{Discussion}

Only in recognizing the same instrument playing different chords did musicians outperform nonmusicians, on average. This result is surprising because it was not predicted that musicians would be better than nonmusicians at auditory discriminations which do not require musical knowledge. In fact, only three nonmusicians performed poorly in this condition, while nine nonmusicians performed fairly well.

It is difficult to assert that musical knowledge is important for successful discrimination of instrument timbre. Only a small difference was found between musicians' and nonmusicians' performances. Despite the poor relationship between timbre discrimination and musical ability, musicians may discriminate instrument timbres more accurately than nonmusicians do because they make the discriminations more often.

Do musicians outperform nonmusicians because they have a more efficient general strategy for encoding the relations between tones, or is their encoding efficiency specific to familiar, diatonic musical structures? The third experiment asks whether musicians can encode both familiar diatonic chords and unfamiliar nondiatonic chords more efficiently than nonmusicians.

\section{EXPERIMENT 3}

Experiment 3 emulated the experiments which used structured and random positions in chess games to study chess masters' skills (Chase \& Simon, 1973b). Both diatonic and nondiatonic chords were presented for discrimination. Diatonic chords are based on a root that serves as a tonal focus or key, and contain only notes from the diatonic major or minor key in force at the moment (Kennedy, 1980). In music-theoretic terms, the notes in diatonic chords are more closely related to the tonic and to each other than to nondiatonic tones, and are "stable" musically. Nondiatonic chords are not based on the principle of key (Kennedy, 1980). They lack a tonal focus, their component notes are less stable, and they occur less frequently in Western tonal music.

Musically trained listeners are sensitive to tonality as an organizing principle in melodies and chords. They judge diatonic tones to be more closely related to each other than to nondiatonic tones (Krumhansl, 1979). Musicians base judgments of the harmonic relations between chords on their functions in musical keys and are highly influenced by the root or key of a context chord in interpreting chords that follow (Krumhansl et al., 1982). Musicians have less training and experience with nondiatonic than with diatonic chords.

Musicians are not expected to have access to appropriate decision strategies for judging nondiatonic chords. They will perform as poorly as nonmusicians in judging identical nondiatonic chords played on different instruments

\section{Method}

Subjects. Listeners were 20 University of Waterloo students, 10 musicians and 10 nonmusicians. None had participated in the previous experiments.

Materials. Two sets of chords were used as stimuli. "Familiar" diatonic chords were Chord Set 2 played on piano and guitar, described in Experiment 1. The five "unfamiliar" nondiatonic chords, shown in Figure 5, were composed of dissonant intervals from the chromatic scale, not characteristic of any diatonic chords in any inversion. Unfamiliar chords were played on a Heinzman piano and a Martin guitar. Experimental tapes were produced, as for Experiment 1 .

Procedure. The procedure used heretofore was employed, with a few alterations. Each listener completed four blocks of trials in one session: two blocks of familiar $(\mathrm{F})$ and two blocks of unfamiliar (U) chords. Two complementary presentation orders were used across listeners, to counterbalance the effects of order: F-U-U-F and U-F-F-U.

\section{Results}

The major finding of Experiment 1 was replicated in this study: Musicians outperformed nonmusicians mainly in judgment of the same chord pair played on different instruments $[F(1,18)=22.46, p<.001]$. The difference was confined to familiar diatonic chords [interaction $F(1,18)=10.30, p<.005]$.

The mean error percentages are plotted for stimuli with the same chord in Figure 6 and with different chords in

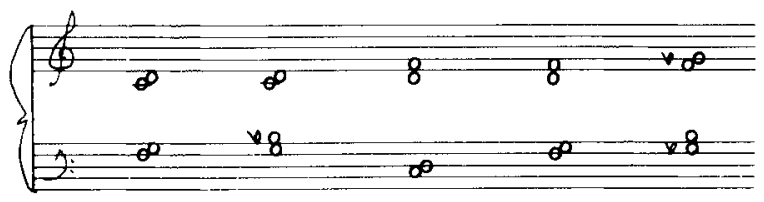

Figure 5. Unfamiliar nondiatonic chords used in Experiment 3. 
Figure 7. The complicated interactions of listeners' musical expertise and the nature of the stimuli are explored in further separate analyses of errors for stimulus pairs with same chords and different chords. Each analysis included training (musicians or nonmusicians) as a betweensubjects variable, and chord structure (familiar or unfamiliar), instrument pairs (same or different), and trial blocks (one or two) as within-subjects variables.

When the chords were the same (Figure 6), musicians outperformed nonmusicians only in detecting the same familiar chord played on different instruments [interaction $\mathrm{F}(1,18)=11.46, \mathrm{p}<.005]$. With familiar chords, musicians' average error rate $(21 \%)$ was reliably lower than nonmusicians' $(76 \%)$ [Tukey studentized range, $p<.05$ ] (Myers, 1972). For identical unfamiliar chords in different timbres, the average error rates for musicians $(67 \%)$ and nonmusicians (79\%) were not significantly different [Tukey studentized range, $\mathrm{p}>.05$ ].

In contrast, musicians were uninfluenced by timbre differences in determining that chords were different, but nonmusicians best determined that chords were different when timbres were different [interaction $F(1,18)=12.53$, $\mathrm{p}<.005]$. This result holds with both diatonic and nondiatonic chords.

As in Experiment 1, musicians showed greater sensitivity $\left(\mathrm{d}^{\prime}=3.51\right)$ than nonmusicians $\left(\mathrm{d}^{\prime}=1.79\right)$ in judging familiar chords. This difference arises entirely in hit rates, the likelihood of calling an identical familiar chord played on different instruments the same. The hit rate was $79 \%$ for musicians and $24 \%$ for nonmusicians. False alarms, calling different familiar chords in the same timbre the same, were identical for each group (11\%) showing that the two groups used similar criteria for these decisions.

Musicians performed no better than nonmusicians when judging unfamiliar chords in different timbres. Musicians' sensitivity $\left(\mathrm{d}^{\prime}=2.57\right)$ did not surpass nonmusicians' $\left(d^{\prime}=1.99\right)$. Equivalent false alarm rates $(7 \%$ and $8 \%$ respectively) show that both groups set similar decision

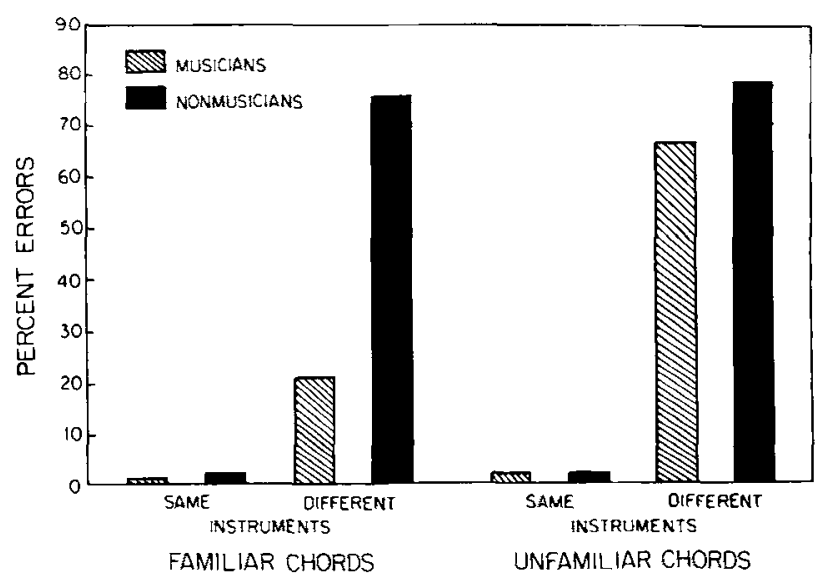

Figure 6. Mean error percentages for chord discriminations with same chord stimuli by musicians and nonmusicians in Experiment 3.

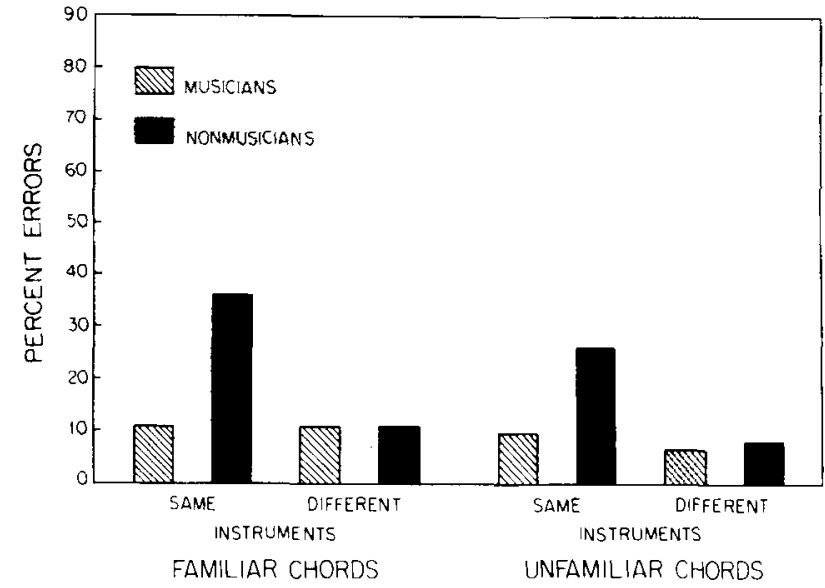

Figure 7. Mean error percentages for chord discriminations with different chord stimuli by musicians and nonmusicians in Experiment 3.

criteria. Their hit rates $(33 \%$ for musicians and $21 \%$ for nonmusicians) show that neither group was highly accurate in identifying the same diatonic chord in different timbres.

Musicians showed greater sensitivity when judging familiar chords $\left(\mathrm{d}^{\prime}=3.51\right)$ than unfamiliar chords $\left(\mathrm{d}^{\prime}\right.$ $=2.57$ ). This difference does not reflect a criterion shift, as false alarm rates were equivalent for familiar (11\%) and unfamiliar (7\%) chords. The difference reflects greater accuracy in identifying the same familiar chord played on different instruments.

Nonmusicians' sensitivity levels were not different for familiar $\left(d^{\prime}=1.79\right)$ and unfamiliar $\left(d^{\prime}=1.99\right)$ chords. Their criteria did not shift, as false alarm rates were equivalent $(11 \%$ and $8 \%$ respectively). Their hit rates were consistently low for the two types of chords ( $24 \%$ and $21 \%$ respectively).

Practice with the task led all listeners to improved accuracy in detecting different chords played on the same instrument in the second block of trials [interaction $\mathrm{F}(1,18)=7.60, \mathrm{p}<.025]$.

\section{Discussion}

Musicians' superiority is confined to familiar diatonic chords. Musicians lacked the specific musical knowledge to encode nondiatonic chords accurately. They judged these chords no more efficiently than nonmusicians.

In contrast, nonmusicians' performance was unrelated to the structure of the chords. Their sole strategy for encoding both familiar and unfamiliar chords involved acoustic rather than conceptual comparison of the chords. Thus, they judged acoustically identical pairs (same chord played on the same instrument) and pairs which were most different (different chords in different instrument timbres) most accurately. This experiment shows that musicians have conceptual knowledge of specific chord structures based on the laws of musical theory which untrained listeners do not share. 
Practice with this task improved performance only in detecting different chords played on the same instrument. Lack of improvement in recognizing the same chord played in different timbres suggests that listeners did not learn with practice the dimensions of musical similarity in chords. Further practice without explicit instruction is not expected to bring nonmusicians up to the level of musicians in performance. Nor would musicians improve their ability to recognize identical unfamiliar chords in different timbres through practice without instruction.

\section{GENERAL DISCUSSION}

Skilled individuals outperform unskilled individuals because the former have perceptual and cognitive skills relevant to the information presented. Musicians outperform nonmusicians in chord judgments because they possess perceptual skills related to their culture's music. Musicians can recognize similarity in familiar diatonic chords despite differences in timbre. Because musicians' judgments take longer, it seems that their decisions are based on musical encoding beyond simpler acoustic analysis. Nonmusicians are less capable of encoding musical structures. They depend heavily on acoustic rather than musical information and can be misled by different timbres (Experiment 1). Thus, nonmusicians discriminate timbre much more accurately than chords (Experiment 2).

Like nonmusicians, musicians had great difficulty recognizing the same nondiatonic chord in different timbres (Experiment 3). Musicians' knowledge of harmony and chord structure enables them to encode diatonic chords and recognize similarity despite timbre differences. Nonmusicians do not encode diatonic chords and are not as good as musicians at attributing the differences in chords played on different instruments to differences in timbre.

What is the nature of musicians' representation of music codes? Sloboda (1976b) suggested that when reading music, musicians code the relations between notes, rather than the actual notes. A relational encoding system has been suggested also for auditory perception of music (e.g., Deutsch \& Feroe, 1981). Musicians can extract a tonal pitch anchor for melodies from context (Cohen, 1978; Cuddy et al., 1979) and are aware of the tonal functions of notes and the intervals formed between notes and their tonal focus (Krumhansl, 1979; Krumhansl \& Shepard, 1979; Meyer, 1956). They are sensitive to notes that do not belong to the diatonic scale underlying a melody (Dowling, 1978). Nonmusicians use pitch in a more concrete way, lacking awareness of these higher order tonal relations (Krumhansl \& Shepard, 1979).

Musicians may process music by encoding tonal relations. By applying the rules of harmony, musicians may extract additional musical information from chords, establishing their structure and tonality by evaluating the tonal function of each note in relation to the others. Since these studies were run, Bharucha and Krumhansl (1983) and Krumhansl, Bharucha, and Castellano (1982) have found that, for musically trained listeners, the harmonic relations between chords are mediated by a process that determines their function in musical keys.

Alternately, musicians may store specific chord structures in the same way as semitone intervals between notes (Siegel \& Siegel, 1977a, 1977b), familiar chess patterns (e.g., Chase \& Simon, 1973a, 1973b), and name referents for letters (Posner, 1969) are learned. Another strategy for discriminating chords could be to determine the tonal relationship between the chords. Information such as pitch height, tonality, and key membership can be compared.

Musicians clearly have strategies that work in determining similarities and differences among chords that reflect the harmony of their culture's music. The musicians' strategies fail when chords lack an underlying harmonic structure. The actual strategies used cannot be determined from these data.

\section{REFERENCES}

Allard, F., Graham, S., \& Paarsalu, M. (1980). Perception in sport: Basketball. Journal of Sport Psychology, 2, 14-21.

Allard, F., \& Henderson, L. (1976). Physical and name codes in auditory memory: The pursuit of an analogy. Quarterly Journal of Experimental Psychology, 28, 475-482.

Allard, F., \& Starkes, J. L. (1980). Perception in volleyball. Journal of Spon Psychology, 2, 22-33.

BENADE, A. H. (1976). Fundamentals of Musical Acoustics. New York: Oxford University Press.

Bharucha, J. J., \& KrumhansL, C. L. (1983). The representation of harmonic structure in music: Hierarchies of stability as a function of context. Cognition, 13, 63-102.

Buros, O. K. (Ed.), (1965). The Mental Measurement Yearbooks. 6th Edition. Highland Park, NJ: The Gryphon Press.

Charness, N. H. (1976). Memory for chess positions: Resistance to interference. Journal of Experimental Psychology: Human Learning \& Memory, 2, 641-653.

Charness, N. H. (1979). Components of skill in bridge. Canadian Journal of Psychology, 33, 1-16.

Chase, W. G., \& Simon, H. A. (1973a). The mind's eye in chess. In W. G. Chase (Ed.), Visual Information Processing. New York: Academic Press

Chase, W. G., \& Simon, H. A. (1973b). Perception in chess. Cognitive Psychology, 4, 55-81.

Cohen, A. J. (1978, April). Inferred sets of pitch in melodic perception. In R. M. Shepard (Chair), Cognitive structure of musical pitch. Symposium conducted at the annual meeting of Western Psychological Association, San Francisco.

Cole, R., Coltheart, M., \& Allard, F. (1974). Memory of a speaker's voice: Reaction time to same- or different-voiced letters. Quarterly Journal of Experimental Psychology, 26, 1-7.

Cuddy, L. L., \& CoHeN, A. J. (1976). Recognition of transposed melodic sequences. Quarterly Journal of Experimental Psychology, 28, 255-270

Cuddy, L. L., Cohen, A. J., \& Dewar, K. M. (1978, June). Judgment of musical intervals: Relations between patterns of accuracy and musical training. Paper presented at the 39 th annual meeting of the Canadian Psychological Association, Ottawa, Canada.

Cuddy, L. L., Cohen, A. J., \& Miller, J. (1979). Melody recognition: The experimental application of musical rules. Canadian Journal of Psychology, 33, 148-157. 
DEGroot, A. D. (1966). Perception and memory versus thought: Some old ideas and recent findings. In B. Kleinmuntz (Ed.), Problem Solving: Research, Method and Theory. New York: John Wiley and Sons.

Deutsch, D. (1978). Interactive effects in memory for harmonic intervals. Perception \& Psychophysics, 24, 7-10

Deutsch, D., \& Feroe, J. (1981). The internal representation of pitch sequences in tonal music. Psychological Review, 6, 503-522.

Deutsch, D., \& Roll, P. L. (1974). Error patterns in delayed pitch comparisons as a function of relational context. Joumal of Experimental Psychology, 103, 1027-1034.

Dewar, K. M., Cuddy, L. L., \& Mewhort, D. J. K. (1977). Recognition memory for single tones with and without context. Journal of Experimental Psychology: Human Learning \& Memory, 3, 60-67.

DowLING, W. J. (1978). Scale and contour: Two components of a theory of memory for melodies. Psychological Review, 85, 341-355.

Dowling, W. J., \& FuJitani, D. S. (1971). Contour, interval and pitch recognition in memory for melodies. Journal of the Acoustical Society of America, 49, 524-531.

Egan, D. E., \& Schwartz, B. J. (1979). Chunking in recall of symbolic drawings. Memory \& Cognition, 7, 149-158.

FreY, P. W., \& ADESMAN, P. (1976). Recall memory for visually presented chess pieces. Memory \& Cognition, 4, 541-547.

Howell, P., \& DaRWIN, C. J. (1977). Some properties of auditory memory for rapid formant transitions. Memory \& Cognition, $\mathbf{5}$, 700-708.

Kaplan, H. L., Macmillan, N. A., \& Creelman, C. D. Tables of $\mathrm{d}^{\prime}$ for variable-standard discrimination paradigms. Behavior Research Methods \& Instrumentation, 10, 796-813.

Kennedy, M. (1980). The Concise Oxford Dictionary of Music. London: Oxford University Press.

KrumhansL, C. L. (1979). The psychological representation of musical pitch in a tonal context. Cognitive Psychology, 11, 346-379.

Krumhansl, C. L., Bharucha, J. J., \& Castellano, M. A. (1982). Key distance effects on perceived harmonic structure in music. Perception \& Psychophysics, 32, 96-108.

Krumhansl, C. L., \& ShePard, R. N. (1979). Quantification of the hierarchy of tonal functions in a diatonic context. Journal of Experimental Psychology: Human Perception \& Performance, 5, 579-594.

Macmillan, N. A., Kaplan, H. L., \& Creelman, C. D. (1977). The psychophysics of categorical perception. Psychological Review, 84, $452-471$.
Meyer, L. B. (1956). Emotion and Meaning in Music. Chicago: University of Chicago Press.

Myers, J. L. (1972). Fundamentals of experimental design. Boston: Allyn and Bacon.

Olson, R. K., \& Hanson, V. (1977). Interference effects in tone memory. Memory \& Cognition, 5, 32-40.

PICK, A. D. (1979, May). Perceiving melodies. Paper presented at the meeting of the Midwestern Psychological Association, Chicago.

PosNer, M. I. (1969). Abstraction and the process of recognition. In G. H. Bower \& J. T. Spence (Eds.). The Psychology of Learning and Motivation: Volume 3. New York: Academic Press.

Posner, M. I., \& WARren, R. E. (1972). Traces, concepts, and conscious constructions. In A. W. Melton \& E. Martin (Eds). Coding Processes in Human Memory. Washington, DC: V. H. Winston and Sons.

SEAShore, C. E. (1919). Seashore's Measures of Musical Talent. Chicago: C. H. Stoelting.

Siegel, J. A., \& Siegel, W. (1977a). Absolute identification of notes and intervals by musicians. Perception \& Psychophysics, 21, 143-152.

Siegel, J. A., \& Siegel, W. (1977b). Categorical perception of tonal intervals: Musicians can't tell sharp from flat. Perception \& Psychophysics, 21, 399-407.

SLoboda, J. A. (1976a). The effect of item position on the likelihood of identification by interference in prose reading and music reading. Canadian Journal of Psychology, 30, 228-237.

SLOBODA, J. A. (1976b). Visual perception of musical notation: Registering pitch symbols in memory. Quarterly Journal of Experimental Psychology, 28, 1-16.

SLoboda, J. A. (1977). Phrase units as determinants of visual processing in music reading. British Journal of Psychology, 68, 117-124.

SLoboda, J. A. (1978). Perception of contour in music reading. Perception, 7, 323-331.

WoLF, T. (1976). A cognitive model of musical sight-reading. Journal of Psycholinguistic Research, 5, 143-171.

(Manuscript received July 23, 1984; revision accepted for publication May 12, 1985.) 